\title{
Preparation and Solubility of Hydroxyapatite
}

\author{
E. C. Moreno,* T. M. Gregory,* and W. E. Brown* \\ Institute for Basic Standards, National Bureau of Standards, Washington, D.C. 20234
}

(August 2, 1968)

\begin{abstract}
Two portions of a synthetic hydroxyapatite (HA), $\mathrm{Ca}_{5} \mathrm{OH}\left(\mathrm{PO}_{4}\right)_{3}$, fully characterized by x-ray, infrared, petrographic, and chemical analyses, were heated at $1,000{ }^{\circ} \mathrm{C}$ in air and steam atmospheres, respectively. Solubility isotherms for these two samples in the system $\mathrm{Ca}(\mathrm{OH})_{2}-\mathrm{H}_{3} \mathrm{PO}_{4}-\mathrm{H}_{2} \mathrm{O}$ were determined in the $p \mathrm{H}$ range 5 to 7 by equilibrating the solids with dilute $\mathrm{H}_{3} \mathrm{PO}_{4}$ solutions. Both samples of HA dissolved stoichiometrically. The activity products $\left(\mathrm{Ca}^{++}\right)^{5}\left(\mathrm{OH}^{-}\right)\left(\mathrm{PO}_{4}^{\overline{5}}\right)^{3}$ and their standard errors-obtained by a least squares adjustment of the measurements $(\mathrm{Ca}$ and $\mathrm{P}$ concentrations and $p \mathrm{H}$ of the saturated solutions) subject to the conditions of electroneutrality, constancy of the activity product, and stoichiometric dissolution-were $3.7_{3} \pm 0.5 \times 10^{-58}$ for the steam-heated HA and $2.5_{1} \pm 0.4 \times 10^{-55}$ for the air-heated HA. Allowance was made in the calculations for the presence of the ion pairs $\left[\mathrm{CaHPO}_{4}\right]^{0}$ and $\left[\mathrm{CaH}_{2} \mathrm{PO}_{4}\right]^{+}$. The higher solubility product for the air-heated $\mathrm{HA}$ is ascribed either to a change in the heat of formation brought about by partial dehydration or to a state of fine subdivision resulting from a disproportionation reaction. The solubility product constants were used to calculate the points of intersection (i.e., singular points) of the two HA solubility isotherms with the isotherms of $\mathrm{CaHPO}_{4} \cdot 2 \mathrm{H}_{2} \mathrm{O}$ and $\mathrm{CaHPO}_{4}$; it was found that the $\mathrm{pH}$ 's of the singular points for the air-heated HA were a full unit higher than those of the steam-heated preparation. Conditions are described for the precipitation of HA crystals suitable for solubility measurements.
\end{abstract}

Key Words: Apatite; hydroxyapatite; calcium phosphates; solubility; solubility isotherms; solubility product.

\section{Introduction}

Hydroxyapatite (HA), $\mathrm{Ca}_{5} \mathrm{OH}\left(\mathrm{PO}_{4}\right)_{3}$, has wide biological and industrial importance. Its physicochemical properties, in particular solubility and detailed crystallographic structure, are directly related to the mineralization processes in biological systems. The various reports in the literature on solubility of HA are contradictory. Clark $[1],{ }^{1}$ on the basis of precipitation and dissolution experiments, concluded that HA has a definite solubility product. Thermodynamic functions for HA (from which a solubility product constant can be calculated) have also been reported $[2,3,4]$. Other reports [5-8], however, claim that systems saturated with respect to $\mathrm{HA}$ do not conform to the principle of a solubility product constant

\footnotetext{
${ }^{*}$ Research Associates from the American Dental Association of the National Bureau of Standards, Washington, D.C. 20234.

This investigation was supported in part by Research Grants DE-01819 and DE-02659 to the American Dental Association from the National Institute of Dental Research and is part of the dental research program conducted by the National Bureau of Standards, in cooperation with the Council on Dental Research of the American Dental Association; the National Institute of Dental Research; the Army Dental Corps; the Aerospace Medical Division, USAF School of Aerospace Medicine; and the Veterans Administration.

${ }^{1}$ Figures in brackets indicate the literature references at the end of this paper.
}

based on the stoichiometry of the salt. Among the models that have been advanced to explain the apparent anomalous behavior of HA in aqueous solutions, those advocating formation of complexes on the surface of the solid $[5,8]$ have received considerable attention. These models implicitly assume that equilibrium between the solid and the liquid phases is not achieved with the crystalline portion of the HA, but instead with surface layers having quite different chemical composition from that of the bulk of the solid. Furthermore, the composition of such layers has been assumed to be constant over a wide range of calcium, phosphorus, and hydrogen concentrations in the liquid phase.

At least part of the problem in the interpretation of data on solubility of $\mathrm{HA}$ is related to the difficulty in preparing pure samples of this compound. So far, the best crystals have been obtained by hydrothermal methods, but the yields are small, the equipment is relatively expensive and the product may contain extraneous phases such as $\beta$-calcium pyrophosphate and/or $\beta$-tricalcium phosphate. Direct precipitation methods usually yield very finely divided 
products, often without the stoichiometric composition of HA. A particularly serious difficulty is contamination by precipitation of the more acid calcium phosphates, among which octacalcium phosphate (OCP), $\mathrm{Ca}_{8} \mathrm{H}_{2}\left(\mathrm{PO}_{4}\right)_{6} \cdot 5 \mathrm{H}_{2} \mathrm{O}$ and its decomposition products are the most difficult to eliminate.

The purposes of this work were (a) to devise a simple method for preparation of HA that would yield sufficiently large and pure crystals so that an unambigious characterization would be possible, (b) to learn whether this compound behaves as a normal chemical compound with unique thermodynamic properties when equilibrated with aqueous solutions, and (c) to establish its solubility isotherm and solubility product constant at $25^{\circ} \mathrm{C}$.

\section{Experimental Methods and Procedures}

In the method of preparation outlined here, the possibility of OCP precipitation is minimized by the use of relatively high temperature and $\mathrm{pH}$. However, $\mathrm{pH}$ values higher than 10 are avoided because they seem to favor the formation of very finely divided precipitates. Other conditions are (a) slow addition of reagents to reduce continuous nucleation, (b) high ionic strength and the presence of acetate ions (a Ca complexing agent) to increase the solubility of HA, and thus to favor formation of larger crystals, (c) use of a large reaction vessel to perform the precipitation without sacrificing yields, and (d) special precautions to avoid contamination with carbonate from the atmosphere or reagents (ammonia was used to control the $\mathrm{pH}$ instead of $\mathrm{NaOH}$ or $\mathrm{KOH}$ because the alkali hydroxides are difficult to obtain free of carbonate contamination).

\subsection{Preparation of HA}

Freshly boiled distilled water and chemically pure salts were used to prepare 2.5 liter of $7.25 \times 10^{-2}$ $M\left(\mathrm{NH}_{4}\right)_{2} \mathrm{HPO}_{4}$ solution and 2.5 liter of $13.33 \times 10^{-2} M$ $\mathrm{Ca}\left(\mathrm{NO}_{3}\right)_{2} \cdot 4 \mathrm{H}_{2} \mathrm{O}$ solution; their $\mathrm{pH}$ 's were adjusted with ammonia gas to 8.5-9. These solutions were stored in borosilicate glass bottles vented through ascarite tubes.

The reaction vessel was a 22-1, 3-neck, borosilicate glass flask. A 4 -ft condenser was attached to one neck; transfer of reagents and materials was done through the other two necks. The top of the condenser was connected by a glass tube to a 6-1, 3-neck flask containing 3 liters of $10 \mathrm{~N} \mathrm{NaOH}$ solution; a check valve permitting outward flow of gases was connected to one neck and a tube, extending into the $\mathrm{NaOH}$ solution and acting as a relief valve, entered through the third neck. The reactant solutions were introduced into the large vessel by a peristaltic pump at a rate of $100 \mathrm{ml} / \mathrm{hr}$. Ammonia gas was passed through an ascarite tower and then bubbled through water before entering the reaction vessel. Samples were withdrawn through a tube that extended to the bottom of the reaction vessel for petrographic examination of the solid and $\mathrm{pH}$ determination of the liquid.

Initially, $9 \mathrm{l}$ of $N$ ammonium acetate solution were boiled in the reaction vessel for about $12 \mathrm{hr}$ to remove $\mathrm{CO}_{2}$; then ammonia gas was passed in until the $\mathrm{pH}$ reached a value between 8.5 and 9 , and the pumping of the phosphate and calcium solutions was started, maintaining vigorous boiling. The $\mathrm{pH}$ was maintained between 8.5 and 9.5 (measured at room temperature) by an adequate flow of $\mathrm{NH}_{3}$ until the total volume of the solutions was pumped into the reaction vessel; then the flow of $\mathrm{NH}_{3}$ was discontinued but boiling was continued for about $3 \mathrm{hr}$. The solid was allowed to settle, the supernatant liquid was withdrawn, about 91 of boiled distilled water were introduced and the mixture was boiled for about $2 \mathrm{hr}$. This washing operation was repeated as was deemed necessary to remove the soluble salts (usually five times). Further washing was done by decantation, using boiled distilled water and short settling periods so as to discard as much as possible the finest fraction of the precipitate. Precautions to avoid contamination by atmospheric $\mathrm{CO}_{2}$ were taken during all these operations. The suspension was then filtered and the solid was dried at $150{ }^{\circ} \mathrm{C}$ for $48 \mathrm{hr}$. As explained in section 3 , a portion of this sample was heated at $1,000{ }^{\circ} \mathrm{C}$ in air and another portion was heated at the same temperature in steam at one atmosphere.

\subsection{Equilibrations}

Equilibrations were made in glass-stoppered bottles, each of which contained $5 \mathrm{~g}$ of $\mathrm{HA}$ and $120 \mathrm{ml}$ of a phosphoric acid solution, by slowly rotating endover-end in a water bath at $25 \pm 0.1{ }^{\circ} \mathrm{C}$. After two weeks, the suspension was transferred to a thermostated saturator, described in an earlier publication [9], in which the $\mathrm{pH}$ of the clear filtered solution was measured. Samples of this solution were taken for calcium and phosphorous analyses. Standardization of the $\mathrm{pH}$-meter (with claimed relative accuracy of $\pm 0.0037 \mathrm{pH}$ units) was made with certified NBS buffer standards [10].

Phosphoric acid solutions used in the equilibrations were prepared from doubly crystallized $2 \mathrm{H}_{3} \mathrm{PO}_{4} \cdot \mathrm{H}_{2} \mathrm{O}$ and freshly boiled conductance water. The molarities of the final solutions were determined by chemical analyses.

\subsection{Calcium and Phosphorus Determinations}

Calcium was determined colorimetrically by the indirect technique described by Banerjee et al. [11]. Phosphorus was determined using the vanadomolybdate reagent of Brabson et al. [12]. In both analyses, samples were compared directly with blanks and standards in a double-beam spectrophotometer.

The analytical errors estimated for the measurements reported here were: $\mathrm{pH}, \pm 0.009$ units; calcium \pm 2.5 percent; and phosphorus, \pm 1.5 percent of the amounts analyzed. 


\section{Characterization of the Solid}

The HA was characterized by petrographic, gasadsorption, chemical, infrared and x-ray methods.

Under the petrographic microscope, the crystals appeared as masses of birefringent, irregularly shaped equant particles up to $5 \mu \mathrm{m}$ in diameter. Present, also, was a minor fraction of thin needles up to $10 \mu \mathrm{m}$ in length. The mean index of refraction (white radiation, $25^{\circ} \mathrm{C}$ ) was 1.636 with a standard error of \pm 0.002 . The material was petrographically homogeneous, both the equant particles up to $5 \mu \mathrm{m}$ in diameter. Present, also, HA. The mean index is lower than the indexes usually given for HA prepared hydrothermally, $N_{\epsilon}=1.644$ and $N_{\omega}=1.651$ [37], but this appears to be a characteristic of precipitated HA. The treatments at $1,000{ }^{\circ} \mathrm{C}$ did not change the mean indexes significantly.

The surface area determined by the BET procedure, ${ }^{2}$ using nitrogen as the adsorbate, yielded a surface area of $6 \mathrm{~m}^{2} / \mathrm{g}$. Although this area is 5 to 10 times larger than that expected from microscopic examination, the agreement is reasonable considering the uncertainties inherent to the two methods.

Chemical analyses yielded $18.22 \pm .27$ percent $\mathrm{P}$ and $39.63 \pm 0.99$ percent $\mathrm{Ca}$, the indicated errors being calculated on the basis of the estimated standard errors of the analytical procedures employed. These values compare with the theoretical values 18.50 percent $\mathrm{P}$ and 39.89 percent $\mathrm{Ca}$ for $\mathrm{HA}$.

The infrared spectrum displayed all the bands characteristic of well-crystallized HA [14]. Small bands in the regions of 1410 and $1640 \mathrm{~cm}^{-1}$ indicated slight contamination with carbonate and moisture, respectively. Analysis by the $\mathrm{W}$ arburg method yielded 0.04 percent $\mathrm{CO}_{2}$.

The $\mathrm{x}$-ray diffraction pattern was sharp and characteristic of that for pure HA [13]. No extraneous peaks were found.

Although the above methods to characterize the HA did not reveal the presence of extraneous phases, when a sample of the $\mathrm{HA}$ was heated to $1,000^{\circ} \mathrm{C}$ for $24 \mathrm{hr}$, the infrared spectrum showed small peaks in the region 920 to $1,200 \mathrm{~cm}^{-1}$. These peaks indicate the presence of $\beta-\mathrm{Ca}_{3}\left(\mathrm{PO}_{4}\right)_{2} \quad$ [14], which presumably formed on heating from a contaminant, an acid calcium phosphate.

A portion of the $\mathrm{HA}$, therefore, was heated at $1,000{ }^{\circ} \mathrm{C}$ for 6 days in room atmosphere to anneal the crystals, to drive off carbon dioxide and moisture, and to convert the less basic calcium phosphate into $\beta-\mathrm{Ca}_{3}\left(\mathrm{PO}_{4}\right)_{2}$. Following the heat treatment, the sample was extracted with $2 \times 10^{-3} M \mathrm{H}_{3} \mathrm{PO}_{4}$ to remove the $\beta$ - $\mathrm{Ca}_{3}\left(\mathrm{PO}_{4}\right)_{2}$. Approximately 10 percent of the sample was dissolved by this treatment.

Another portion of the HA was subjected to the same heat treatment but in the presence of one atmosphere of water vapor, and then extracted with the $\mathrm{H}_{3} \mathrm{PO}_{4}$ solution.

\footnotetext{
${ }^{2}$ Measurement made by Dr. W. V. Loebenstein, NBS.
}

The infrared spectra of the heated samples were very similar, both corresponding to pure HA [14] but the height of the peak at $3,570 \mathrm{~cm}^{-1}$ was considerably greater for the steam-heated sample, indicating either a more uniform environment for the $\mathrm{OH}^{-}$group in this sample or actually a higher content of $\mathrm{OH}^{-}$in the crystals.

Another sample of HA, referred to here as "as prepared" was synthesized according to the method described above, but it was not subjected to high temperature treatment.

\section{Calculation of Solubility Product Constants}

The solubility product constants,

$$
K_{s p}=\left(\mathrm{Ca}^{++}\right)^{5}\left(\mathrm{OH}^{-}\right)\left(\mathrm{PO}_{4} \equiv\right)^{3}
$$

where parentheses denote ionic activities, were calculated by a procedure very similar to the one described elsewhere [9]. The values are listed in tables 1 , 2 , and 5. However, it was recognized that the best values to be derived from such data must take into account more completely the propagation of errors and the proper weight of the measurements. A more refined method was devised, therefore, for these calculations which entails the simultaneous adjustment of the weighted observables-i.e., calcium and phosphorus concentrations and pH's in the various equilibrated solutions plus the initial concentration of $\mathrm{H}_{3} \mathrm{PO}_{4}$ - and the determination of a parameter which yields best estimates of $K_{s p}$. The main features of the method follow the general least-squares adjustment discussed by Deming [15] and they are similar to those recently presented by Wentworth et al. [16] for the calculation of complexing constants using spectrophotometric data. However, for the present work, two or three condition functions were used instead of one. A detailed account of the method will be given elsewhere [17]. It suffices here to give the three condition functions used in this investigation, based on electroneutrality, the solubility product for HA, and congruency in the dissolution of the solid, respectively,

$$
\begin{gathered}
2[M-\tau]+\frac{\left(\mathrm{H}^{+}\right)}{f_{\mathrm{H}^{+}}}+\mathrm{R} \tau-\frac{K_{w}}{\left(\mathrm{H}^{+}\right), f_{\mathrm{OH}^{-}}}-\frac{[P-\tau] Q_{1}}{Q_{2}}=\mathrm{O} \\
{[M-\tau]^{5} f_{\mathrm{Ca}^{++}}^{5_{-+}}\left[\frac{K_{3}(P-\tau)}{\left(\mathrm{H}^{+}\right) Q_{2}}\right]^{3} \frac{K_{w}}{\left(\mathrm{H}^{+}\right)}-S=\mathrm{O}} \\
\frac{[M]}{P-P_{0}}-\frac{5}{3}=\mathrm{O}
\end{gathered}
$$

in which $M$ and $P$ are the total molar concentrations of $\mathrm{Ca}$ and $\mathrm{P}$ in solution, respectively; $\left(\mathrm{H}^{+}\right)$is the activity of the hydrogen ion; $f$ is the molar activity coefficient of the subscripted species; $\mathrm{K}_{w}$ and $\mathrm{K}_{3}$ 
are the dissociation constants of water and the third ionization constant of $\mathrm{H}_{3} \mathrm{PO}_{4}$, respectively; $P_{0}$ is the initial molar concentration of $\mathrm{H}_{3} \mathrm{PO}_{4} ; S$ is the parameter to be calculated, its value being the best estimate of $K_{s p}$; the fraction $5 / 3$ is the theoretical $\mathrm{Ca} / \mathrm{P}$ ratio in $\mathrm{HA} ; \tau$ is the total molar concentration of $\mathrm{Ca}$ or $\mathrm{P}$ present as the ion pairs $\left[\mathrm{CaHPO}_{4}\right]^{\circ}$ and $\left[\mathrm{CaH}_{2} \mathrm{PO}_{4}\right]^{+}[9]$ and it is defined, as are the quantities $L, Q_{1}, Q_{2}$, and $R$, by the expressions,

$$
\begin{aligned}
& \tau=(1 / 2 M+1 / 2 P+L) \\
& -\sqrt{(1 / 2 M+1 / 2 P+L)^{2}-M P} \\
& L=\frac{Q_{2}}{2 f_{\mathrm{Ca}^{+}}\left[K_{x}+\frac{K_{y}\left(H^{+}\right)}{K_{2} f_{\mathrm{H}_{2} \mathrm{PO}_{4}^{-}}}\right]} \\
& Q_{1}=\frac{\left(H^{+}\right)}{K_{2} f_{\mathrm{H}_{2} \mathrm{PO}_{4}}}+\frac{2}{f_{\mathrm{HPO}_{\overline{4}}}}+\frac{3 K_{3}}{\left(H^{+}\right) f_{\mathrm{PO} \overline{\overline{4}}}} \\
& Q_{2}=\frac{\left(H^{+}\right)^{2}}{K_{1} K_{2}}+\frac{\left(H^{+}\right)}{K_{2} f_{\mathrm{H}_{2} \mathrm{PO}_{4}^{-}}}+\frac{1}{f_{\mathrm{HPO}_{\overline{4}}}}+\frac{K_{3}}{\left(H^{+}\right) f_{\mathrm{PO}}} \\
& R=\frac{1}{1+\frac{K_{x} K_{2} f_{\mathrm{H}_{2} \mathrm{PO}}-}{K_{y}\left(H^{+}\right)}} .
\end{aligned}
$$

In eqs (4-8), $K_{1}$ and $K_{2}$ are the first and second ionization constants of $\mathrm{H}_{3} \mathrm{PO}_{4}$, respectively, and $K_{x}$ and $K_{y}$ are the association constants for the ion-pairs $\left[\mathrm{CaHPO}_{4}\right]^{\circ}$ and $\left[\mathrm{CaH}_{2} \mathrm{PO}_{4}\right]^{+}$. A list of the numerical values for the various constants used in this investigation is given in the appendix.

The three condition functions, eqs (1-3), were used to obtain the best estimates of $K_{s p}$ for the preheated hydroxyapatites (in air and steam). Condition (3), defining stoichiometric dissolution, was excluded for the calculations with HA "as prepared" because phosphate was adsorbed in some of these equilibrations, as explained in section 5.1.

Equation (4) was obtained from the simultaneous solution of eqs (9) and (10) which describe the equilibria involved in the formation of ion pairs. Calling $X$ the concentration of $\left[\mathrm{CaHPO}_{4}\right]^{\circ}$ and $Y$ that of $\left[\mathrm{CaH}_{2} \mathrm{PO}_{4}\right]^{+}$,

$$
\begin{gathered}
X=\frac{K_{x}[M-\tau][P-\tau] f_{\mathrm{Ca}^{++}}}{Q_{2} f_{x}} \\
Y=\frac{K_{y}[M-\tau][P-\tau] f_{\mathrm{Ca}^{++}}\left(\mathrm{H}^{+}\right)}{Q_{2} K_{2} f_{y}}
\end{gathered}
$$

in which $f_{x}$ and $f_{y}$ are the activity coefficients for the species $\left[\mathrm{CaHPO}_{4}\right]^{\circ}$ and $\left[\mathrm{CaH}_{2} \mathrm{PO}_{4}\right]^{+}$, respectively.

The ionic strength, $\mu$, was defined in these calculations by
$\mu=2[M-\tau]+1 / 2\left[\frac{\left(\mathrm{H}^{+}\right)}{f_{\mathrm{H}^{+}}}+\frac{K_{w}}{\left(\mathrm{H}^{+}\right) f_{\mathrm{OH}^{-}}}+R \tau+\frac{(P-\tau) Q_{3}}{Q_{2}}\right]$

in which

$$
Q_{3}=\frac{\left(\mathrm{H}^{+}\right)}{K_{2} f_{\mathrm{H}_{2} \mathrm{PO}_{4}^{-}}}+\frac{4}{f_{\mathrm{HP}_{4}}}+\frac{9 K_{3}}{\left(\mathrm{H}^{+}\right) f_{\mathrm{PO}_{4}}} .
$$

The values for the ionic activity coefficients were calculated by the use of the Debye-Hückel theory using the distances of the closet approach given in the appendix. The iterative procedure, starting with unitary activity coefficients, reported in previous publications $[9,18]$ was used for these calculations. The activity coefficients $f_{x}$ and $f_{\mathrm{H}_{3} \mathrm{PO}_{4}}$ were taken to be unity, and it was assumed that $f_{y}=f_{\mathrm{H}_{2} \mathrm{PO}_{4}}$.

\section{Results}

\subsection{Solubility of HA}

The experimental results for the steam-heated and air-heated preparations are given in tables 1 and 2 , respectively, along with the values of $K_{s p}$ calculated from these results using the activity product that appears as the leading term in eq (2). The spread in $K_{s p}$ in each table is acceptably low even though the average $K_{s p}$ for the steam-heated material, table 1, is three orders of magnitude less than that for the air-heated material, table 2 . The other tests that can be applied to these data-apparent electroneutrality unbalance, stoichiometry of the dissolution reaction, and smoothness of the plots of $\mathrm{Ca}$ or $\mathbf{P}$ versus $\mathrm{pH}-$ also show deviations which are within the anticipated experimental errors, thus vouching for the validity of the results. In tables 3 and 4 are given the adjusted values for the three observables, $\mathrm{Ca}, \mathrm{P}$, and $\mathrm{pH}$, and the adjusted values of $K_{s p}$, electroneutrality and the ratio $\mathrm{Ca} / \mathrm{P}$ of the dissolution reactions. It is clear that the adjustments in the $\mathrm{Ca}, \mathrm{P}$, and $\mathrm{pH}$ values are within their anticipated experimental errors. The fact that these adjustments are small is further confirmation

\begin{tabular}{|c|c|c|c|c|c|}
\hline \multirow{2}{*}{$\begin{array}{c}\text { Initial } \\
{\left[\mathrm{H}_{3} \mathrm{PO}_{4}\right]} \\
M \times 10^{3}\end{array}$} & \multicolumn{3}{|c|}{ Composition of saturated solution } & \multirow{2}{*}{$\begin{array}{c}\mathrm{Ca} / \mathrm{P} \\
\text { Dissol. Reac. }\end{array}$} & \multirow{2}{*}{$K_{s p} \times 10^{58}$} \\
\hline & $\mathrm{pH}$ & $\stackrel{[\mathrm{P}]}{M \times 10^{3}}$ & $\underset{M \times 10^{3}}{[\mathrm{Ca}]}$ & & \\
\hline \multirow[t]{2}{*}{$\begin{array}{l}4.17 \\
2.00 \\
1.00 \\
1.00 \\
0.30\end{array}$} & \multirow[t]{2}{*}{$\begin{array}{l}5.049 \\
5.40_{0} \\
5.69_{9} \\
5.74_{7} \\
6.22_{1}\end{array}$} & \multirow[t]{2}{*}{$\begin{array}{l}6.19 \\
2.94 \\
1.50 \\
1.48 \\
0.46\end{array}$} & \multirow[t]{2}{*}{$\begin{array}{r}3.16 \\
1.49 \\
0.79 \\
.78 \\
.25\end{array}$} & $\begin{array}{l}1.56 \\
1.58 \\
1.59 \\
1.64 \\
1.50\end{array}$ & $\begin{array}{l}3.7_{0} \\
5.1_{4} \\
5.2_{1} \\
9.7_{1} \\
2.9_{9}\end{array}$ \\
\hline & & & & Avg. $1.57 \pm 0.02^{\mathrm{a}}$ & $\quad 5.3_{5} \pm 2.6_{2}^{\mathrm{a}}$ \\
\hline
\end{tabular}
of the internal consistency of the data. We believe that the best estimate of the two $K_{s p}$ 's obtained by the adjustment procedure (tables 3 and 4 ), which weights the experimental measurements according to their errors, constitute better values for the solubility products than the simple unweighted mean values, given in tables 1 and 2 .

TABLE 1. Solubility of steam-heated HA, unadjusted quantities 
TABLE 2. Solubility of air-heated HA, unadjusted quantities

\begin{tabular}{|c|c|c|c|c|c|}
\hline \multirow{2}{*}{$\begin{array}{c}\text { Initial } \\
{\left[\mathrm{H}_{3} \mathrm{PO}_{4}\right]} \\
M \times 10^{3}\end{array}$} & \multicolumn{3}{|c|}{ Composition of saturated solution } & \multirow{2}{*}{$\begin{array}{c}\mathrm{Ca} / \mathrm{P} \\
\text { Dissol. Reac. }\end{array}$} & \multirow{2}{*}{$K_{s p} \times 10^{55}$} \\
\hline & $\mathrm{pH}$ & $\begin{array}{c}{[\mathrm{P}]} \\
M \times 10^{3}\end{array}$ & $\begin{array}{c}{[\mathrm{Ca}]} \\
M \times 10^{3}\end{array}$ & & \\
\hline \multirow[t]{2}{*}{$\begin{array}{r}2.04 \\
1.98 \\
0.99 \\
1.01 \\
1.01 \\
0.50 \\
.10 \\
.05\end{array}$} & \multirow[t]{2}{*}{$\begin{array}{l}5.76_{8} \\
5.79_{0} \\
6.11_{9} \\
6.12_{0} \\
6.13_{0} \\
6.40_{0} \\
7.07_{1} \\
7.36_{2}\end{array}$} & \multirow[t]{2}{*}{$\begin{array}{r}3.02 \\
3.00 \\
1.39 \\
1.46 \\
1.51 \\
0.75 \\
.19 \\
.11\end{array}$} & \multirow[t]{2}{*}{$\begin{array}{r}1.62 \\
1.57 \\
0.76 \\
.83 \\
.84 \\
.49 \\
.15 \\
.09\end{array}$} & $\begin{array}{l}1.65 \\
1.53 \\
1.90 \\
1.85 \\
1.70 \\
1.95 \\
1.60 \\
1.62\end{array}$ & $\begin{array}{l}2.5_{7} \\
3.1_{3} \\
2.3_{6} \\
4.1_{3} \\
5.6_{2} \\
3.8_{2} \\
3.6_{0} \\
2.2_{7}\end{array}$ \\
\hline & & & & Avg. $1.72 \pm 0.02^{a}$ & $3.4_{4} \pm 0.1^{\mathrm{a}}$ \\
\hline
\end{tabular}

a Standard errors in the means.

TABLE 3. Solubility of steam-heated HA, adjusted quantities

\begin{tabular}{|c|c|c|c|c|c|c|c|c|}
\hline \multirow{2}{*}{$\begin{array}{r}\text { Initial } \\
{\left[\mathrm{H}_{3} \mathrm{PO}_{4}\right.} \\
M \times 10^{4}\end{array}$} & \multicolumn{3}{|c|}{$\begin{array}{l}\text { Composition of saturated } \\
\text { solution }\end{array}$} & \multirow{2}{*}{$\begin{array}{l}\mathrm{Ca} / \mathrm{p} \\
\text { Dissol. } \\
\text { Reac. }\end{array}$} & \multirow{2}{*}{$r^{\mathrm{a}}$} & \multirow{2}{*}{$\begin{array}{l}\text { Ionic } \\
\text { strength } \\
\mu \times 10^{3}\end{array}$} & \multirow{2}{*}{$\begin{array}{c}\text { Apparent } \\
\text { charge } \\
\text { imbalance } \\
M \times 10^{6}\end{array}$} & \multirow{2}{*}{$\begin{array}{r}K_{s p} \\
\times 10^{58}\end{array}$} \\
\hline & $\mathrm{pH}$ & $\underset{M \times 10^{0}}{[\mathrm{P}]}$ & $\underset{M \times 10^{3}}{[\mathrm{Ca}]}$ & & & & & \\
\hline \multirow[t]{2}{*}{$\begin{array}{l}4.28 \\
2.00 \\
1.02 \\
1.00 \\
0.31\end{array}$} & \multirow[t]{2}{*}{\begin{tabular}{|l}
$5.05_{7}$ \\
$5.38_{9}$ \\
$5.69_{2}$ \\
$5.72_{0}$ \\
$6.23_{6}$
\end{tabular}} & \multirow[t]{2}{*}{$\begin{array}{l}6.13 \\
2.89 \\
1.48 \\
1.45 \\
0.46\end{array}$} & \multirow[t]{2}{*}{$\begin{array}{r}3.10 \\
1.47 \\
0.77 \\
.75 \\
.25\end{array}$} & \multirow[t]{2}{*}{$\begin{array}{l}1.68 \\
1.67 \\
1.67 \\
1.67 \\
1.68\end{array}$} & \multirow[t]{2}{*}{$\begin{array}{r}0.03_{8} \\
.02_{4} \\
.01_{7} \\
.01_{8} \\
.01_{2}\end{array}$} & \multirow[t]{2}{*}{$\begin{array}{l}9.10 \\
4.40 \\
2.32 \\
2.28 \\
0.80\end{array}$} & $\begin{array}{r}0.0 \\
-.1 \\
.0 \\
-.3 \\
.0\end{array}$ & $\begin{array}{l}3.7_{3} \\
3.9_{2} \\
3.9_{2} \\
5.3_{1} \\
3.8_{5}\end{array}$ \\
\hline & & & & & & & $S=3.7$ & $=0.4^{\mathrm{b}}$ \\
\hline
\end{tabular}

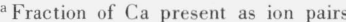

${ }^{\text {b }}$ Standard error from least-squares adjustment.

TABLE 4. Solubility of air-heated HA, adjusted quantities

\begin{tabular}{|c|c|c|c|c|c|c|c|c|}
\hline \multirow{2}{*}{$\left.\begin{array}{c}\text { Initial } \\
{\left[\mathrm{H}_{3} \mathrm{PO}_{4}\right.} \\
M \times 10^{3}\end{array}\right]$} & \multicolumn{3}{|c|}{$\begin{array}{c}\text { Composition of saturated } \\
\text { solution }\end{array}$} & \multirow{2}{*}{$\begin{array}{c}\mathrm{Ca} / \mathrm{P} \\
\text { Dissol. } \\
\text { Reac. }\end{array}$} & \multirow{2}{*}{$r^{\mathrm{a}}$} & \multirow{2}{*}{$\begin{array}{c}\text { Ionic } \\
\text { strength } \\
\mu \times 10^{3}\end{array}$} & \multirow{2}{*}{$\begin{array}{l}\text { Apparent } \\
\text { charge } \\
\text { imbalance } \\
M \times 10^{6}\end{array}$} & \multirow{2}{*}{$\begin{array}{r}K_{s p} \\
\times 10^{55}\end{array}$} \\
\hline & $\mathrm{pH}$ & $\underset{M \times 10^{3}}{[\mathrm{P}]}$ & $\underset{M \times 10^{3}}{[\mathrm{Ca}]}$ & & & & & \\
\hline $\begin{array}{l}2.06 \\
2.02 \\
0.96 \\
.99 \\
1.00 \\
0.50 \\
.11 \\
.05\end{array}$ & $\begin{array}{l}5.77_{2} \\
5.788_{5} \\
6.113_{3} \\
6.10_{2} \\
6.10_{6} \\
6.400_{0} \\
7.039_{6} \\
7.39_{3}\end{array}$ & $\begin{array}{r}3.02 \\
2.94 \\
1.42 \\
1.47 \\
1.49 \\
0.77 \\
.19 \\
.11\end{array}$ & $\begin{array}{r}1.59 \\
1.55 \\
0.78 \\
.81 \\
.82 \\
.44 \\
.14 \\
.09\end{array}$ & $\begin{array}{l}1.67 \\
1.68 \\
1.69 \\
1.68 \\
1.67 \\
1.68 \\
1.68 \\
1.67\end{array}$ & $\begin{array}{c}0.03_{4} \\
.03_{4} \\
.02_{7} \\
.02_{8} \\
.02_{8} \\
.02_{4} \\
.01_{7} \\
.01_{4}\end{array}$ & $\begin{array}{l}4.75 \\
4.64 \\
2.39 \\
2.48 \\
2.52 \\
1.42 \\
0.48 \\
0.33\end{array}$ & $\begin{array}{r}0.0 \\
-. .1 \\
.0 \\
-.2 \\
-.5 \\
.0 \\
.0 \\
.0\end{array}$ & $\begin{array}{l}2.5_{1} \\
2.5_{7} \\
2.5_{2} \\
2.8_{0} \\
3.2_{6} \\
2.6_{6} \\
2.6_{2} \\
2.5_{3}\end{array}$ \\
\hline & & & & & & & $S=2.5$, & $=0.37^{6}$ \\
\hline
\end{tabular}

${ }^{\text {a }}$ Fraction of $\mathrm{Ca}$ present as ion pairs.

${ }^{b}$ Standard error from least-squares adjustment.

The large difference between the two $K_{s p}$ values (tables 3 and 4) probably relates to structural changes induced by the heat treatments, as discussed later.

Also listed in tables 3 and 4 are the values for ionic strength and the fraction, $r$, of Ca present in the form of ion pairs given by $\tau / M$. The gradual increase in $r$ with decreasing $\mathrm{pH}$ relates to the increase in $\mathrm{Ca}$ and $\mathrm{P}$ concentrations, and is mostly the result of an increase in the concentration of the ion-pair $\left[\mathrm{CaH}_{2} \mathrm{PO}_{4}\right]^{+}$.

Results of the solubility experiments for the "as prepared" HA are shown in table 5 . The large variation in the $K_{s p}$ values in table 5 is believed to relate to the presence of other calcium phosphates less basic than HA; evidence for this type of contamination is presented in section 3 . The data also suggest the presence of an anion foreign to the system $\mathrm{Ca}(\mathrm{OH})_{2}-\mathrm{H}_{3} \mathrm{PO}_{4}-\mathrm{H}_{2} \mathrm{O}$ as evidenced by an apparent positive electroneutrality unbalance which is far beyond experimental error for the three treatments with $\mathrm{pH}$ 's above 6 . This may have been caused by carbonate since the infrared spectrum showed small $\mathrm{CO}_{3}=$ peaks.

TABLE 5. Solubility of "as prepared" HA, unadjusted quantities

\begin{tabular}{|c|c|c|c|c|}
\hline \multirow{2}{*}{$\begin{array}{c}\text { Initial } \\
{\left[\mathrm{H}_{3} \mathrm{PO}_{4}\right]} \\
M \times 10^{3}\end{array}$} & \multicolumn{3}{|c|}{ Final solution composition } & \multirow[b]{2}{*}{$K_{s p} \times 10^{58}$} \\
\hline & $\mathrm{pH}$ & $\stackrel{[\mathrm{P}]}{M \times 10^{3}}$ & $\underset{M \times 10^{3}}{[\mathrm{Ca}]}$ & \\
\hline $\begin{array}{r}7.82 \\
3.05 \\
0.49 \\
.20 \\
.05\end{array}$ & $\begin{array}{l}4.74_{9} \\
5.26_{9} \\
6.60_{2} \\
7.05_{1} \\
7.45_{6}\end{array}$ & $\begin{array}{r}10.17 \\
3.43 \\
0.23 \\
.06 \\
.03\end{array}$ & $\begin{array}{r}5.11 \\
1.67 \\
0.16 \\
.10 \\
.11\end{array}$ & $\begin{array}{r}0.8_{4} \\
1.5_{4} \\
11.9_{4} \\
10.9_{4} \\
251.2\end{array}$ \\
\hline
\end{tabular}

Interpretation of the data in table 5 is further complicated by sorption phenomena; for example the phosphorus concentrations in the solutions for the last three entries of table 5 are less than the initial $\mathrm{H}_{3} \mathrm{PO}_{4}$ concentrations. A systematic study of this type of surface phenomenon with finely divided HA has been reported elsewhere [20]. Although some of the $K_{s p}$ values in table 5 are in the range of those given in table 1 for the steam-heated HA, the three at the higher $\mathrm{pH}$ 's are abnormally large. Furthermore, the calculated adjustments of the measurements, not shown here, were so large as to invalidate the least squares procedure. As a result, little weight is given to the set of data in table 5 . They give some confirmation in the low $\mathrm{pH}$ range of the results obtained for the steam-heated HA and they illustrate how the solutions can be made supersaturated in the high $\mathrm{pH}$ range by the presence of calcium phosphates less basic than HA.

The phosphorus concentrations of the solutions saturated with respect to the preheated HA's, tables 1 and 2, are plotted against their corresponding $\mathrm{pH}$ 's in figure 1. Similar plots for solutions saturated with respect to $\mathrm{CaHPO}_{4} \cdot 2 \mathrm{H}_{2} \mathrm{O}$ (DCPD) $[17,18]$ and $\mathrm{CaHPO}_{4}$ (DCPA) [19] at $25{ }^{\circ} \mathrm{C}$ are also shown in the same tigure. The HA curves were extrapolated (dotted lines) to meet the intersection points A, B, C, and $\mathrm{D}$ in figure 1 . These four points correspond to singular points between the preheated HA's and DCPD or DCPA. The chemical compositions of the solutions at the singular points were calculated by solving eq (13) for $\left(\mathrm{H}^{+}\right)$through a method of successive approximations,

$$
\begin{aligned}
\frac{2\left(\mathrm{H}^{+}\right)^{2} K_{\mathrm{DC}} K}{f_{\mathrm{Ca}^{+}}}+\frac{\left(\mathrm{H}^{+}\right)}{f_{\mathrm{H}^{+}}}+ & \frac{R K_{x} K_{\mathrm{DC}}}{1-R} \\
& -\frac{Q_{1}}{\left(\mathrm{H}^{+}\right)^{2} K}-\frac{K_{w}}{\left(\mathrm{H}^{+}\right) f_{\mathrm{OH}^{-}}}=0
\end{aligned}
$$




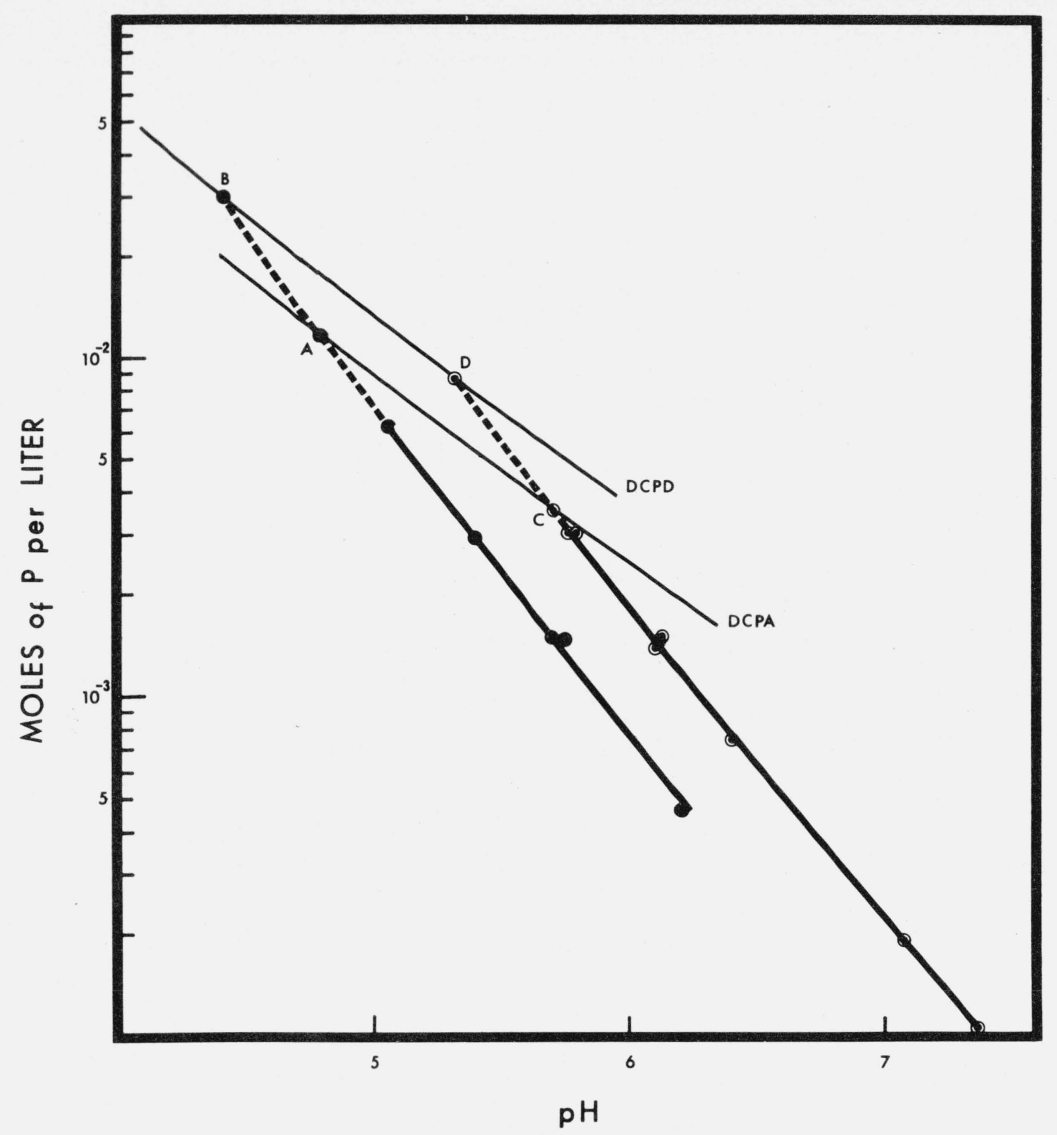

FIGURE 1. Solubility isotherms of steam-heated HA, full circles, and air-heated HA, open circles, at $25^{\circ} \mathrm{C}$.

The two lighter curves are the isotherms of $\mathrm{CaHPO}_{4} \cdot 2 \mathrm{H}_{2} \mathrm{O}$ [17], DCPD, and $\mathrm{CaHPO}_{4}$ [19], DCPA. Compositions of the calculated singular points $\mathrm{A}, \mathrm{B}, \mathrm{C}$, and $\mathrm{D}$ are given in table 6 .

in which $K_{\mathrm{DC}}$ represents the solubility product constant for either DCPD or DCPA, as the case may be, and $K$ is defined by

$$
K=\left[\frac{K_{s p}}{K_{3}^{3} K_{w} K_{\mathrm{DC}}^{5}}\right]^{1 / 2}
$$

The value for $\left(\mathrm{H}^{+}\right)$obtained from eq (13) was then used to obtain the numerical value of $\tau$ since, for saturation with respect to either DCPD or DCPA,

$$
\tau=\frac{K_{x} K_{\mathrm{DC}}}{1-R} .
$$

The concentrations of calcium and phosphorus are obtained from eqs (16) and (17), respectively.

$$
\begin{gathered}
M=\frac{\left(\mathrm{H}^{+}\right)^{2} K_{\mathrm{DC}} K}{f_{\mathrm{Ca}^{++}}}+\tau \\
P=\frac{Q_{2}}{\left(\mathrm{H}^{+}\right)^{2} K}+\tau .
\end{gathered}
$$

The chemical compositions of the solutions at the four singular points, calculated in the foregoing fashion, are given in table 6. Considerably higher concentrations of $\mathrm{Ca}$ and $\mathrm{P}$ (and lower $\mathrm{pH}$ 's) are found at the singular points of the preheated HA's with DCPD than at the corresponding singular points with DCPA; the same pattern is observed for the fractions of Ca present as ion pairs ( $r$ in the table). These results are a consequence of the higher solubility of DCPD [17, 18] relative to the anhydrous salt at $25{ }^{\circ} \mathrm{C}$ [19]. The most striking differences in the compositions at the singular points, however, are brought about by the solubility of the HA itself. Thus, a full $\mathrm{pH}$ unit difference exists between the singular points of air-heated and steamheated HA with either of the two dicalcium phosphates; changes in calcium and phosphorus concentrations by factors of about 3.5 and 4, respectively, parallel this $\mathrm{pH}$ difference. If, as it is apparent from the present results, the solubility of HA depends upon the previous history of the sample, it is nearly impossible to predict the composition of singular points between a precipitated HA and other calcium phosphates without fully characterizing the solubility properties of the HA involved. 
TABLE 6. Solution compositions at singular points

\begin{tabular}{|c|c|c|c|c|}
\hline Solid phases & $\mathrm{pH}$ & $M \stackrel{[\mathrm{P}]}{\times 10^{3}}$ & $\begin{array}{c}{[\mathrm{Ca}]} \\
M \times 10^{3}\end{array}$ & $r^{a}$ \\
\hline $\begin{array}{l}\text { DCPD + HA (air) } \ldots \ldots \ldots \ldots \ldots \ldots \\
\text { DCPD + HA (steam) } \ldots \ldots \ldots \ldots \ldots . \\
\text { DCPA + HA (air) } \ldots \ldots \ldots \ldots \ldots \ldots \ldots \\
\text { DCPA + HA (steam) } \ldots \ldots \ldots \ldots \ldots \ldots\end{array}$ & $\begin{array}{l}5.31_{5} \\
4.41_{0} \\
5.70_{1} \\
4.79_{1}\end{array}$ & $\begin{array}{r}8.64 \\
30.21 \\
3.53 \\
11.54\end{array}$ & $\begin{array}{r}4.43 \\
15.09 \\
1.85 \\
5.80\end{array}$ & $\begin{array}{r}0.05_{4} \\
.10_{9} \\
.03_{6} \\
.05_{8}\end{array}$ \\
\hline
\end{tabular}

${ }^{\text {a }}$ Fraction of Ca present as ion pairs.

Although the weight loss in our sample was not measured, slight weight losses have been reported [22] in the range 1,000 to $1,100{ }^{\circ} \mathrm{C}$ for synthetic HA samples heated gradually from 25 to $1,200{ }^{\circ} \mathrm{C}$; these losses occurred without alteration in the $\mathrm{x}$-ray patterns. Also, it has been reported [23] that at $1,200^{\circ} \mathrm{C}$ in air, disproportionation of HA into tricalcium phosphate and tetracalcium phosphate occurs according to the reaction,

$$
\begin{aligned}
2 \mathrm{Ca}_{5} \mathrm{OH}\left(\mathrm{PO}_{4}\right)_{3} \rightarrow 2 \alpha-\mathrm{Ca}_{3}\left(\mathrm{PO}_{4}\right)_{2} & \\
& +\mathrm{Ca}_{4} \mathrm{O}\left(\mathrm{PO}_{4}\right)_{2}+\mathrm{H}_{2} \mathrm{O} .
\end{aligned}
$$

The x-ray powder diffraction pattern of the air-heated sample was the same as that of HA, but it is impossible to rule out a partial disproportionation.

In view of the foregoing considerations, there are two explanations for the higher solubility of the airheated HA: (1) Reversal of the disproportionation reaction [18] when the sample is returned to an aqueous system might yield very finely divided HA with an unusually high solubility because of surface energy contribution, or (2) loss of $\mathrm{OH}^{-}$ions by dehydration during heating of the solid, without destruction of the HA lattice, might yield crystals with higher free energy. Evidently, the process responsible for the increased solubility is not readily reversible, since otherwise the values for the $K_{s p}$ of the two preparations would have been the same. Therefore, the equilibria attained with the air-heated HA must have been metastable relative to the more stable form of HA. This would require that the rate of dissolution of the air-heated $\mathrm{HA}$ was higher than the rate of precipitation of the more stable salt.

The $K_{s p}$ values for the two kinds of preheated apatites correspond to a difference of about $16 \mathrm{~kJ} / \mathrm{mol}$ $(3.9 \mathrm{kcal} / \mathrm{mol})$ in the standard free energies of formation. If it were assumed that the standard heat of formation is the same for both compounds, the observed difference in free energy would correspond to about $59 \mathrm{~J} / \mathrm{mol} \mathrm{K}(14 \mathrm{cal} / \mathrm{mol} \mathrm{K})$ less entropy in the air-heated apatite than in the steam-heated salt. This difference appears too large to be associated with a change in entropy resulting from vacancies or ordering. For this reason it is believed that the difference in solubility is mostly related to a difference in their heat contents.

\section{Discussion}

\subsection{Solubility of HA}

The solubility data given in tables 1 and 2 for the two preheated HA samples are consistent with stoichiometric dissolution represented by the reaction $\mathrm{Ca}_{5} \mathrm{OH}\left(\mathrm{PO}_{4}\right)_{3} \rightleftarrows 5 \mathrm{Ca}^{++}+\mathrm{OH}^{-}+3 \mathrm{PO}_{4}$. It is believed that saturation conditions were obtained in the twoweek equilibrations as evidenced by the smooth curves obtained in the plots of calcium concentration versus $\mathrm{pH}$ (fig. 1), calcium concentration versus phosphorus concentration (not shown in this paper), and a reasonable constancy in the ionic activity product for HA. The success of the adjustment procedure described in section 4 is additional evidence that the parameters $S$, tables 3 and 4 , are valid solubility product constants for the preheated hydroxyapatites.

The higher solubility product constant obtained for the HA heated in air, relative to the product obtained for the sample heated in steam, is most probably due to structural changes induced by the thermal treatment. Such changes might relate in part to the statistically disordered structure of HA described by Kay et al. [21], originating from small displacements of the $\mathrm{OH}^{-}$groups from the mirror planes in the space group $\mathrm{P}_{3} / \mathrm{m}$. If this were purely an entropy effect, such disorder would tend to stabilize the lattice; the steamheated sample, therefore, would have to be the disordered one. However, it is difficult to see why heating $\mathrm{HA}$ in air would induce more order in the $\mathrm{OH}^{-}$groups than would be obtained by heating in steam. A more likely explanation is that heating in air results in loss of $\mathrm{OH}^{-}$groups by partial dehydration of the HA. Indeed, the infrared spectra tend to substantiate this alternative. Whereas the half width of the peak at $3,570 \mathrm{~cm}^{-1}$ corresponding to the $\mathrm{OH}^{-}$stretching mode, was essentially the same for both preheated hydroxyapatites, its height for the steam-heated HA was almost twice that of the air-heated HA.

\subsection{Singular Points}

A system of two solid phases in equilibrium with an aqueous phase in the ternary system $\mathrm{Ca}(\mathrm{OH})_{2}$ $\mathrm{H}_{3} \mathrm{PO}_{4}-\mathrm{H}_{2} \mathrm{O}$ is characterized by zero degrees of freedom (under conditions of constant temperature and pressure). Such singular points are important in solubility diagrams because they correspond to points where there is a change in the relative stability of the two solid phases. Thus, with reference to table 6 , in saturated solutions with pH's below 4.33, DCPD is more stable than the steam-heated HA; in solutions with pH's above 4.33, steam-heated HA is more stable than DCPD. The greater solubility of the air-heated HA has the effect of increasing the $\mathrm{pH}$ of the singular points with the dicalcium phosphates by about one $\mathrm{pH}$ unit relative to those with steamheated HA. If an apatite comparable to the air-heated HA were formed in oral environments, its greater solubility would extend the stability ranges of the two dicalcium phosphates to conditions which occur in saliva in vivo. 
In the concentration ranges covered by the present experiments, the degree of ion-pair formation varied from about 1.4 percent (at the highest $\mathrm{pH}$ ) to about 3.4 percent (at the lowest $\mathrm{pH}$ ) of the total calcium concentration. In view of the uncertainty, both theoretical and experimental in these calculations for nonsymmetrical electrolytes, the formation of ionpairs in the experimental segments of the solubility isotherms for HA is not considered significant. However, in more acid solutions, such as those of the calculated singular points, the ion-pair formation does become significant.

\subsection{Stoichiometry and Potential Diagrams}

The stoichiometry of a solid calcium phosphate equilibrated with aqueous solutions is easily revealed by the use of "potential diagrams" $[24,25,26]$. These are solubility diagrams in which the coordinates are functions of the chemical potentials of the components, $\mathrm{Ca}(\mathrm{OH})_{2}$ and $\mathrm{H}_{3} \mathrm{PO}_{4}$, in solution. For example, if the quantity $-\log \left(\mathrm{Ca}^{++}\right)\left(\mathrm{OH}^{-}\right)^{2}$ is plotted against $-\log$ $\left(\mathrm{H}^{+}\right)^{3}\left(\mathrm{PO}_{4}\right)$, the saturation condition is defined by a straight line and the absolute value of its slope corresponds to the reciprocal of the $\mathrm{Ca} / \mathrm{P}$ ratio in the solid. This kind of diagram is illustrated in figure 2 with calculations based on the data for the two preheated apatites (tables 1 and 2). Similar calculations were made with data from other investigators and these are plotted in the same diagram. The slopes and their standard errors, of the regression lines for the air-heated and steam-heated apatites shown in figure 2 correspond to apparent $\mathrm{Ca} / \mathrm{P}$ ratios of 1.69 and 1.68 with standard errors of 0.02 and 0.07 , respectively. These ratios agree with the theoretical ratio for HA, 1.67, and the ratio, 1.68 obtained by chemical analysis of the untreated solid. In view of these facts, the relatively low value obtained for the $\mathrm{Ca} / \mathrm{P}$ ratio in the dissolution reaction, 1.57, of the steam-heated preparation, table 1 , must be ascribed to experimental errors. It is to be noted that the $\mathrm{Ca} / \mathrm{P}$ ratio calculated from dissolution involves a difference between two experimental measurements.

\subsection{Comparison With Reported Data}

Clark [1] reported a value of 57.75 as his best estimate of $p K_{s p}$ (the negative logarithm of $K_{s p}$ ) of $\mathrm{HA}$ at $25{ }^{\circ} \mathrm{C}$. (The actual value he reported, 115.5, is based on the formula $\mathrm{Ca}_{10}(\mathrm{OH})_{2}\left(\mathrm{PO}_{4}\right)_{6}$ rather than the formula $\mathrm{Ca}_{5} \mathrm{OH}\left(\mathrm{PO}_{4}\right)_{3}$ used here.) His systems consisted of HA precipitated by mixing dilute solutions of $\mathrm{Ca}(\mathrm{OH})_{2}$ and $\mathrm{H}_{3} \mathrm{PO}_{4}$ at $90{ }^{\circ} \mathrm{C}$; he kept the resulting suspensions at that temperature for $120 \mathrm{hr}$ and reequilibrated them at $25{ }^{\circ} \mathrm{C}$ for $90 \mathrm{hr}$. The $K_{s p}$ corresponding to his $p K_{s p}$ value of 57.75 is $1.78 \times 10^{-58}$, which is in good agreement with the value $3.73 \times 10^{-58}$ reported here for the steam-heated $\mathrm{HA}$. The individual values reported by Clark range from $0.53 \times 10^{-58}$ to $7.59 \times 10^{-58}$. Even though Clark's data, as plotted in the chemical potential diagram, figure 2 , have some scatter, it is apparent that they approximate closely the same line as our data for the steam-heated HA. The same author observed that equilibrations made at $25{ }^{\circ} \mathrm{C}$ with $\mathrm{HA}$ precipitated at $40{ }^{\circ} \mathrm{C}$ resulted in large apparent supersaturations with respect to the

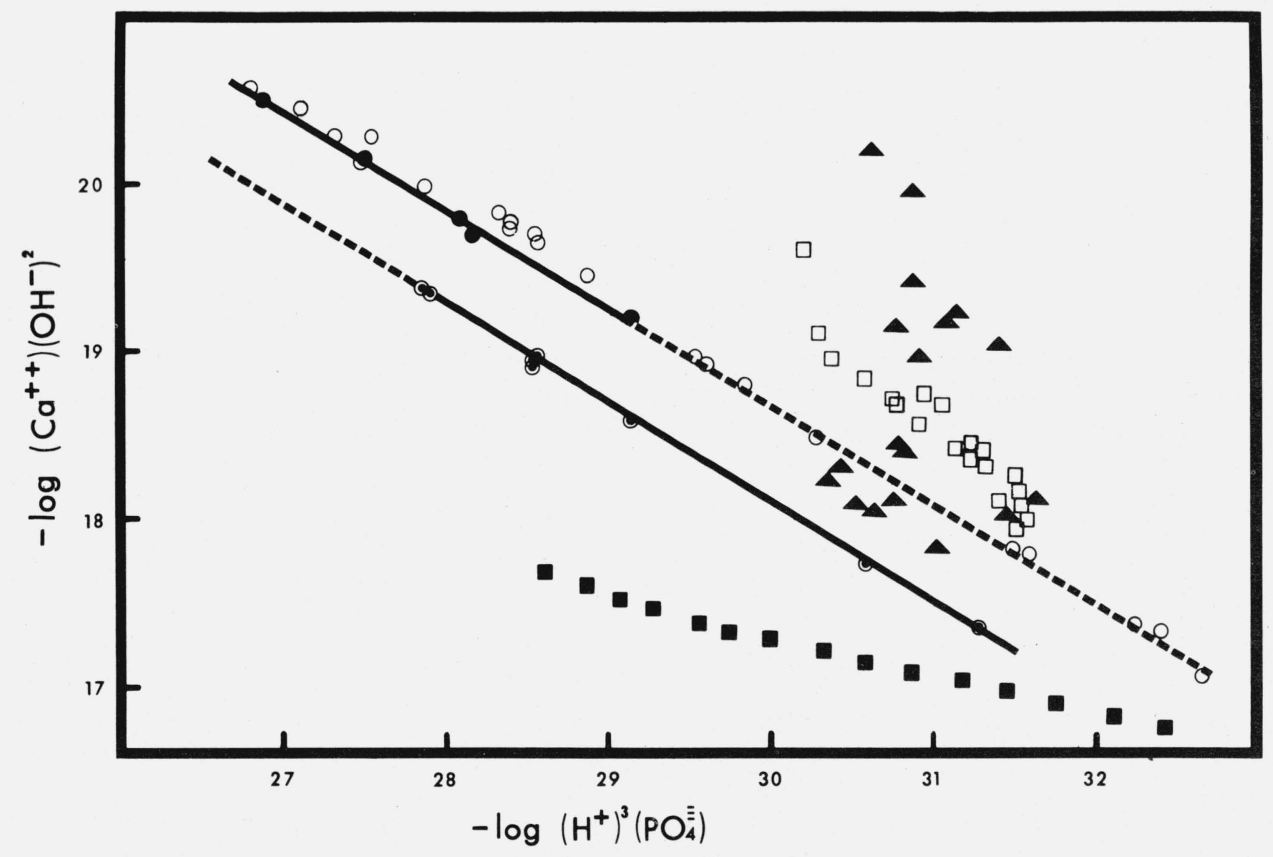

Figure 2. Potential plot, calcium hydroxide versus phosphoric acid.

, steam-heated HA; $\odot$, air-heated HA; $\bigcirc$, data from Clark [1]; $\boldsymbol{\Lambda}$, data from Levinskas and Neuman [31]; $\square$, data from Rootare et al. [5] at $25{ }^{\circ} \mathrm{C}$; $\mathbf{C}$, data from Rootare et al. [5] at $40{ }^{\circ} \mathrm{C}$. 
values for $K_{s p}$ given above. In light of present knowledge, one would expect that those precipitates contained some of the more acid calcium phosphate which are more soluble than HA. Thus, the more reliable of Clark's results agree with those reported here for steam-heated HA. We consider it significant that such good agreement was obtained between materials prepared by precipitation from aqueous systems aild a material subjected to annealing at $1,000{ }^{\circ} \mathrm{C}$ in a steam atmosphere. This suggests that the $K_{s p}$ value obtained for the steam-heated material is characteristic of any well-crystallized HA.

A solubility product constant for HA was calculated from the following thermodynamic quantities: $\Delta H_{f}^{\circ}=-13,439 \mathrm{~kJ} / \mathrm{mol}(-3,212 \mathrm{kcal} / \mathrm{mol})$ reported by Smirnova et al. [2] for $\mathrm{HA}$ which had also been heated at $1,000^{\circ} \mathrm{C}$ in the presence of steam; $S^{\circ}=780.7 \mathrm{~J} / \mathrm{mol} \mathrm{K}$ $(186.6 \mathrm{cal} / \mathrm{mol} \mathrm{K})$ reported by Egan and Wakefield [4] for another HA treated in a similar way, and standard entropies of formation of the elements and standard free energies of formation of ions reported in NBS Publications [27, 28]. The product thus obtained, based on the formula $\mathrm{Ca}_{5} \mathrm{OH}\left(\mathrm{PO}_{4}\right)_{3}$, is of the order $10^{-57}$.

This result, too, is considered to be in good agreement with the order of magnitude given here, $10^{-58}$, for the steam-heated apatite, considering the uncertainties in some of the thermodynamic quantities used and the great effect that small variations in these quantities have on the $K_{s p}$ calculated in this fashion.

The foregoing results are not in agreement with those of Levinskas [29], Levinskas and Neuman [6], and Neuman and Neuman [7] who concluded that synthetic preparations of $\mathrm{HA}$ equilibrated in aqueous solutions do not obey the solubility-product constant principle. One of the hydroxyapatites (L-apatite) most extensively studied by these authors was a commercial preparation of fine particle size, $68 \mathrm{~m}^{2} / \mathrm{g}$. The large surface areas of their materials could introduce difficulties in the interpretation of solubility studies. However neither theoretically [30] nor experimentally [20] do sorption phenomena invalidate the application of the solubility product constant to systems equilibrated with HA. It should be pointed out that the sample of HA (L-apatite) used by Neuman and coworkers had a refractive index of 1.605 [5] which is much too low for a well-crystallized HA; in addition, their preparation was contaminated with calcite, contained 0.28 percent sulfate and 0.8 percent $\mathrm{CO}_{2}$ [5]. No history is given for the synthesis of L-apatite, but the analytical results clearly show the heterogeneity of the sample. Under these circumstances, reactions other than simple dissolution and precipitation of $\mathrm{HA}$ are to be expected, and their involved kinetics is a burden for sound interpretations of solubility studies. The adoption of the ion-activity product $\left(\mathrm{Ca}^{++}\right)\left(\mathrm{HPO}_{4}^{=}\right)$to characterize $\mathrm{HA}$ systems, as suggested by Neuman and co-workers [7, 29] cannot be justified on theoretical bases [30]. Our recalculation of their data [31] plotted in figure 2 shows that the points are widely scattered, do not define a single line, and cannot be used to derive a reliable $K_{s p}$ for a solid of any $\mathrm{Ca} / \mathrm{P}$ ratio.

Rootare, Deitz, and Carpenter [5] reported results on solubility studies done with several commercial and laboratory-prepared samples. They observed wide variations in the calculated ion-activity products for $\mathrm{HA}$; these were explained by postulating formation of a surface complex according to the reactions,

$$
\begin{aligned}
\mathrm{Ca}_{10}\left(\mathrm{PO}_{4}\right)_{6}(\mathrm{OH})_{2}+6 \mathrm{H}_{2} \mathrm{O} \rightleftarrows & \left.4 \mathrm{Ca}_{2}\left(\mathrm{HPO}_{4}\right)(\mathrm{OH})_{2}\right] \\
& +2 \mathrm{Ca}^{++}+2 \mathrm{HPO}_{4}^{=}
\end{aligned}
$$

$\mathrm{Ca}_{2}\left(\mathrm{HPO}_{4}\right)(\mathrm{OH})_{2} \rightleftarrows 2 \mathrm{Ca}^{++}+\mathrm{HPO}_{4}^{=}+2 \mathrm{OH}^{-}$

It is true, as they claim, that the ionic product calculated according to eq (20) showed less variability ( $p K$ values from 24.6 to 26.8) than those calculated for $\mathrm{HA}$ on the basis of the formula unit $\mathrm{Ca}_{10}\left(\mathrm{OH}_{2}\left(\mathrm{PO}_{4}\right)_{6}\right.$ ( $p K$ from 108 to 120 ). However, the mechanism postulated by Rootare et al. is open to the following criticisms: (a) Although the composition of the HA surface does not have to conform necessarily to the stoichiometry of the bulk solid, there is no a priori reason to postulate that certain surface compositions will prevent equilibrium with the crystalline HA lattice [30]; (b) It is highly improbable that the surface of HA equilibrated in aqueous solutions has a definite composition independent of the composition of the aqueous medium [20]; (c) If a definite composition is ascribed to the "surface complex" and the solubility product principle is applied according to its stoichiometry, it is mandatory that such species be considered as another solid phase (i.e., has constant molar free energy and stoichiometry [30]); then, in the light of eqs (19) and (20), the system would have zero degrees of freedom (in the system $\mathrm{Ca}(\mathrm{OH})_{2}-\mathrm{H}_{3} \mathrm{PO}_{4}-\mathrm{H}_{2} \mathrm{O}$ ) under fixed temperature and pressure [30] so that the solution composition could not vary as observed by them; (d) It can be easily shown that the equilibrium conditions [19] and [20], as given by Rootare et al., also imply equilibrium with respect to the HA solid phase; (e) Of the 12 samples used by Rootare et al., only four were petrographically homogeneous [5]; the rest were contaminated with calcite varying from traces to about 1 percent, with sulfate varying from 0.006 to 0.29 percent and, with the exception of two, all the samples contained carbonate in significant amounts; only the four samples prepared in the laboratory showed a refractive index approaching the one expected for well-crystallized $\mathrm{HA}$; one of the latter, $\mathrm{P}-20$, probably contained less basic calcium phosphates as evidenced by a $\mathrm{Ca} / \mathrm{P}$ ratio of 1.583 and the report by Gee [32] that pyrophosphate was formed upon heating it at $600{ }^{\circ} \mathrm{C}$ for $60 \mathrm{hr}$.

The results reportec by Rootare et al. [5] form two distinct populations when plotted in figure 2 . The regression line for the points at $25^{\circ} \mathrm{C}$ (the point 30.20 , 19.61 excluded) has a slope of -0.778 , which would correspond to a ratio of $\mathrm{Ca} / \mathrm{P}=1.28$ in the solid phase. 
The points from treatments at $40{ }^{\circ} \mathrm{C}$ appear to define two lines with slopes -0.309 and -0.211 which would correspond to $\mathrm{Ca} / \mathrm{P}$ ratios of 3.24 and 4.74 in the solid. If equilibrium with respect to $\mathrm{Ca}_{2}\left(\mathrm{HPO}_{4}\right)(\mathrm{OH})_{2}$ had been established, as claimed by Rootare et al. [5], lines with slope of $-0.5(\mathrm{Ca} / \mathrm{P}=2)$ should have been defined by their data in the potential plot. The fact that their data define two or three $\mathrm{Ca} / \mathrm{P}$ ratios, none of which correspond to their postulated surface complex, along with the other criticisms listed above, argue very strongly against the existence of the surface complex hypothesized by them. LaMer [8] reexamined the data of Rootare et al. [5] and came to the conclusion that the product, $\left(\mathrm{Ca}^{++}\right)\left(\mathrm{HPO}_{4}^{=}\right)$showed the least variation. However, for the reasons given above, this is not an adequate basis for any conclusions regarding the nature of the equilibrating solid phase.

In the light of the foregoing results and discussion we conclude that our samples of preheated HA did equilibrate according to the stoichiometry of HA and according to the usual solubility product principles, that the steam-heated HA yielded a solubility constant usable as a frame of reference for well-crystallized $\mathrm{HA}$, and that most of the difficulties reported in the literature on this matter relate to contamination of the solid and lack of equilibrium between the solution and the solid.

\section{Appendix}

Ionic activity coefficients were calculated from the extension of the Debye-Hückel limiting law,

$$
\log f_{i}=-\frac{A Z_{i}^{2} \sqrt{\mu}}{1+\mathrm{Ba}_{i} \sqrt{\mu}} .
$$

The values used [33] for the temperature-dependent constants $A$ and $B$ were 0.5092 and $0.3286 \times 10^{8}$, respectively; those for the parameters $a_{i}$ [34] were $\mathrm{Ca}^{++}, 6 \times 10^{-8} \mathrm{~cm} ; \mathrm{H}_{2} \mathrm{PO}_{4}^{-}, \mathrm{HPO}_{4}^{=}$, and $\mathrm{PO}_{\overline{4}}, 4 \times 10^{-8}$ $\mathrm{cm} ; \mathrm{H}^{+}, 9 \times 10^{-8} \mathrm{~cm}$; and $\mathrm{OH}^{-}, 3.5 \times 10^{-8} \mathrm{~cm}$.

The values used for the three ionization constants of $\mathrm{H}_{3} \mathrm{PO}_{4}$ were $K_{1}, 7.10_{8} \times 10^{-3}[35] ; K_{2}, 6.31_{8} \times 10^{-8}$ [36]; $K_{3}, 4.73 \times 10^{-13}$ [37]; and for $K_{w}, 1.012 \times 10^{-14}$ [38]. The association constants used in this paper are defined by

$$
K_{x}=\frac{\left[\mathrm{CaHPO}_{4}\right]^{\circ}}{\left(\mathrm{Ca}^{++}\right)\left(\mathrm{HPO}_{4}^{=}\right)} \quad K_{y}=\frac{\left(\mathrm{CaH}_{2} \mathrm{PO}_{4}^{+}\right)}{\left(\mathrm{Ca}^{++}\right)\left(\mathrm{H}_{2} \mathrm{PO}_{4}^{-}\right)}
$$

with values [17] $K_{x}, 244.0$; and $K_{y}, 8.20$.

The points in the potential plot (fig. 2) corresponding to the data of Rootare et al. [5], at $40{ }^{\circ} \mathrm{C}$ were calculated using the following constants: $K_{1}, 5.99_{6} \times 10^{-3}$ [35]; $K_{2}, \quad 6.60_{7} \times 10^{-8}[36] ; \quad K_{3}, \quad 7.58_{6} \times 10^{-13} \quad[39] ;$ $K_{w}, 2.936 \times 10^{-14}[38] ; A$, eq $(21), 0.524_{1}[33] ;$ and $B, 0.3318 \times 10^{8}[33]$.

\section{References}

[1] Clark, J. S., Can. J. Chem. 33, 1696 (1955).

[2] Smirnova, F. G., Illarionov, V. V., and Vol'fkovich, S. I., Russian J. Inorg. Chem. 7, 920 (1962).

[3] Jacques, J. K., J. Chem. Soc. 3820 (1963).

[4] Egan, E. P., Jr., Wakefield, Z. T., and Elmore, K. L., J. Am. Chem. Soc. 73, 5579 (1951).

[5] Rootare, H. M., Deitz, V. R., and Carpenter, F. G., J. Colloid Sci. 17, 179 (1962).

[6] Levinskas, G. J., and Neuman, W. F., J. Phys. Chem. 59, 164 (1955).

[7] Neuman, W. F., and Neuman, M. W., The Chemical Dynamics of Bone Mineral, p. 30 (University of Chicago Press, Chicago, Ill., 1958).

[8] LaMer, V. K., J. Phys. Chem. 66, 973 (1962).

[9] Moreno, E. C., Gregory, T. M., and Brown, W. E., J. Res. NBS $70 A$ (Phys. and Chem.) No. 6, 545 (1966).

[10] Bates, R. G., J. Res. NBS 66A (Phys. and Chem.) No. 2, 179 (1962).

[11] Banerjee, D. K., Budke, C. C., and Miller, F. D., Anal. Chem. 33, 418 (1961).

[12] Brabson, J. A., Dunn, R. L., Epps, E. A., Jr., Hoffman, W. M., and Jacob, K. D., J.A.O.A.C. 41, 517 (1958).

[13] ASTM Powder diffraction file, Card No. 9-432.

[14] Fowler, B. O., Moreno, E. C., and Brown, W. E., Arch. Oral Biol. 11, 477 (1966).

[15] Deming, W. E., Statistical Adjustment of Data (John Wiley \& Sons, Inc., New York, 1943).

[16] Wentworth, W. E., Hirsch, W., and Chen, E., J. Phys. Chem. 71, 218 (1967).

[17] Gregory, T. M., Moreno, E. C., and Brown, W. E. (Abstract), Internat. Assoc. Dental Res., 45th General Meeting, Washington, D.C. (1967).

[18] Moreno, E. C., Brown, W. E., and Osborn, G., Soil Sci. Soc. Amer. Proc. 24, 94 (1960).

[19] McDowell, H., Ph. D. Thesis, Howard University, Washington, D.C. (1967).

[20] Avnimelech, Y., Moreno, E. C., and Brown, W. E. (Abstract), Internat. Assoc. Dental Res., 45th General Meeting, Washington, D.C. (1967).

[21] Kay, M. I., Young, R. A., and Posner, A. S. Nature 204, 1050 (1964).

[22] Egan, E. P., Jr., Wakefield, Z. T., and Elmore, K. L., J. Am. Chem. Soc. 72, 2418 (1950).

[23] Bredig, M. A., Franck, H. H., and Füldner, H., Z. Elecktrochem. 39, 959 (1933).

[24] Aslyng, H. C., Royal Vet. and Agric. Coll. Copenhagen, Denmark, Yearbook Reprint, pp. 1-50 (1954).

[25] Moreno, E. C., Lindsay, W. L., and Osborn, G., Soil Sci. 90, 59 (1960).

[26] MacGregor, J., and Brown, W. E., Nature 205, 359 (1965).

[27] National Bureau of Standards. Selected Values of Chemical Thermodynamic Properties, Circ. 500 (1952).

[28] National Bureau of Standards. Technical Note 270-1 (1965) and Technical Note 270-2 (1966).

[29] Levinskas, G. J., Ph. D. Thesis, University of Rochester, New York (1953).

[30] Brown, W. E., Moreno, E. C., and Gregory, T. M., Thermodynamics of hydroxyapatite solubility. In preparation.

[31] Table 2 of reference 6.

[32] Gee, A., Proc. Third Tech. Session on Bone Char. p. 337 (1953).

[33] Manov, G. G., Bates, R. G., Hamer, W. J., and Acree, S. F., J. Am. Chem. Soc. 65, 1765 (1943).

[34] Kielland, J., J. Am. Chem. Soc. 59, 1675 (1937).

[35] Bates, R. G., J. Res. NBS 47, 127 (1951) RP2236.

[36] Bates, R. G., and Acree, S. F., J. Res. NBS 34, 373 (1945) RP1648.

[37] Tennessee Valley Authority. Chem. Eng. Report No. 8 (1950).

[38] Harned, H. S., and Owen, B. B., The physical chemistry of electrolytic solutions, p. 645 (equation 15-3-7a), (Reinhold Publishing Corporation, New York, 1958).

[39] Bjerrum, N., and Unmack, A., Kgl. Danske Videnskab. Selskab., Math-fys. Medd. 9, 5 (1929).

(Paper 72A6-527) 